\title{
Preoperative dexamethasone for acute post-thoracotomy analgesia: a randomized, double-blind, placebo-controlled study
}

\author{
Kyoung-Woon Joung ${ }^{1}$, Hyeong Ryul Kim², Wook-Jong Kim', Ye Ji Lim³ ${ }^{3}$ Jae Won Kim³, Eun-Ho Lee ${ }^{3^{*}}$ (1)
} and In-Cheol Choi ${ }^{1}$

\begin{abstract}
Background: The analgesic effects of dexamethasone have been reported previously, and the present study determined the effects of preoperative dexamethasone on postoperative pain in patients who received thoracotomy.

Methods: Forty patients participated in this randomized, double-blind study. All patients received either dexamethasone via a $0.1 \mathrm{mg} / \mathrm{kg}$ intravenous bolus before anesthetic induction or an equal volume of saline. Postoperative analgesia was provided to both groups via epidural patient-controlled analgesia (PCA), which consisted of $250 \mu \mathrm{g}$ of sufentanil in $250 \mathrm{~mL}$ of ropivacaine $(0.18 \%)$ for $72 \mathrm{~h}$. The primary outcome was the cumulative consumption of epidural PCA at postoperative 24 and $72 \mathrm{~h}$. The secondary outcomes were the pain intensity scores during resting and coughing at postoperative 24 and $72 \mathrm{~h}$, quality of recovery, total amount of rescue analgesics required, and length of hospital stay.
\end{abstract}

Results: No significant differences was observed in the consumption of epidural PCA between the control and dexamethasone infusion groups at $24 \mathrm{~h}(63.6[55.9-72.7]$ vs. $68.5[60.2-89.0] \mathrm{ml}, P=0.281)$ and $72 \mathrm{~h}(199.4$ [172.4$225.1]$ vs. 194.7 [169.1-252.2] $\mathrm{ml}, P=0.890)$. Moreover, there was no significant difference in the pain intensity scores during resting and coughing at postoperative 24 and $72 \mathrm{~h}$, quality of recovery, total amount of rescue analgesics required, and length of hospital stay.

Conclusion: A single intravenous administration of dexamethasone during the preoperative period does not reduce opioid consumption and post-thoracotomy pain.

Trial registration: The study was registered at http://cris.nih.go.kr (KCT0000359) and was conducted from December 2011 to October 2012.

Keywords: Analgesia, Dexamethasone, Epidural, Thoracotomy

\section{Background}

Many patients experience intense pain following thoracotomy. Although thoracic epidural analgesia (TEA) is believed to be the most effective single technique for controlling post-thoracotomy pain [1], it often fails to treat post-thoracotomy pain. Thus, anesthesiologists require some adjuvant treatments for thoracotomy pain relief.

\footnotetext{
*Correspondence: leho@naver.com

${ }^{3}$ Department of Anesthesiology and Pain Medicine, Asan Medical Center,

University of Ulsan College of Medicine, Seoul, Korea

Full list of author information is available at the end of the article
}

Recent studies have suggested that glucocorticoids are beneficial as postoperative analgesic agents because of their anti-inflammatory property in various surgeries [26]. Moreover, a recent meta-analysis suggested that dexamethasone is an effective adjunct to multimodal strategies for reducing postoperative pain and opioid consumption [7]. However, the efficacy of dexamethasone in controlling post-thoracotomy pain remains uncertain.

Our hypothesis is that the preoperative administration of dexamethasone may be an effective adjuvant treatment for post-thoracotomy pain like other surgeries. Thus, in this randomized, controlled double-blind study,

(C) The Author(s). 2018 Open Access This article is distributed under the terms of the Creative Commons Attribution 4.0 International License (http://creativecommons.org/licenses/by/4.0/), which permits unrestricted use, distribution, and 
we investigated whether the preoperative administration of this drug reduces post-thoracotomy pain during the recovery period.

\section{Methods \\ Study population}

After obtaining approval from our institutional review board (2011-0812) and written informed consent from each patient, 40 patients with American Society of Anesthesiologists physical status I-II for more than 20 years, who were scheduled for thoracotomy under general anesthesia, were enrolled in this prospective study. Exclusion criteria included an emergent infection for < 1 month before surgery; contraindications for dexamethasone or opioid use; severe cardiac, renal, or hepatic diseases; psychiatric disorder; uncontrolled diabetes mellitus; and the preoperative use of analgesics or steroids. The study was registered at http://cris.nih.go.kr (KCT0000359) and conducted between December 2011 and October 2012.

Patients were randomly allocated to two groups using computer-generated codes that were maintained in sequentially numbered opaque envelopes. On the morning of the surgery and before the induction of anesthesia, the envelopes were opened by a blinded nurse or anesthesiologist who subsequently prepared either dexamethasone or saline in coded $5-\mathrm{mL}$ syringes. All other anesthesiologists involved in patient management or data collection were blinded to the group assignment. Just before the induction of anesthesia, each patient was administered an intravenous (IV) bolus injection of $0.1 \mathrm{mg} / \mathrm{kg}$ dexamethasone or an equal volume of saline.

\section{Anesthetic management and surgical technique}

Before the anesthetic induction, all patients underwent thoracic epidural catheterization at the T6-7 intervertebral space using the loss-of-resistance technique. General anesthesia was induced using a bolus IV injection of $0.2 \mathrm{mg} / \mathrm{kg}$ etomidate and the continuous infusion of propofol and remifentanil using a target-controlled infusion pump. Furthermore, a bolus IV injection of $0.8 \mathrm{mg} / \mathrm{kg}$ rocuronium was administered to perform orotracheal intubation. After the intubation, patients were ventilated to normocapnia using 50\% oxygen and air. The effect-site concentration of propofol was adjusted to maintain the bispectral index value between 40 and 60 (using 0.1$0.2 \mu \mathrm{g} / \mathrm{mL}$ steps), and remifentanil was administered to maintain the heart rate within $15 \%$ of the pre-induction value and systolic arterial blood pressure within $20 \%$ of the baseline value (using $0.5 \mathrm{ng} / \mathrm{mL}$ steps). If the mean arterial blood pressure and cardiac index showed a more than $20 \%$ decrease from the preoperative values, vasoconstrictors or inotropics, such as phenylephrine, dopamine, or norepinephrine, were administered. All patients underwent standard posterolateral thoracotomy by the same surgical team. The serratus anterior muscle was preserved, and the sixth rib was removed. During thoracotomy, all patients received one-lung ventilation using a double-lumen endotracheal tube. Postoperative analgesia was administered to both groups via epidural patient-controlled analgesia (PCA), consisting of $250 \mu \mathrm{g}$ of sufentanil in $250 \mathrm{~mL}$ of ropivacaine $(0.18 \%)$ administered as a 2 -mL bolus dose with a 15 -min lockout period; a maximum of $10 \mathrm{~mL}$ was administered over $1 \mathrm{~h}$, and $2 \mathrm{~mL}$ of background infusion was maintained for $72 \mathrm{~h}$ postoperatively. Epidural PCA was started during the closure of the muscle layer. The administration of all drugs was stopped 5 min before the end of surgery, and extubation was performed in case of a response to verbal commands, spontaneous respiratory rate $>12$ breaths/minutes, and end-tidal carbon dioxide partial pressure $<45 \mathrm{mmHg}$. Patients were admitted to the intensive care unit within 5 min of tracheal extubation. Both groups received rescue analgesics, if needed, during the postoperative period, and the total amount of rescue medication was recorded.

\section{Outcome evaluation}

The primary outcome was the cumulative consumption of epidural PCA at postoperative 24 and $72 \mathrm{~h}$. We believe that the cumulative consumption of epidural PCA is more objective than the pain score in assessing postoperative pain; therefore, we determined epidural PCA consumption as the primary outcome. The secondary outcomes included the pain intensity scores during resting and coughing, incidence of shoulder pain, total amount of rescue analgesics administered, and incidence of nausea and vomiting at postoperative 24 and $72 \mathrm{~h}$, as well as the quality of recovery, duration of intensive care unit (ICU) stay and length of hospital stay. Moreover, we determined the incidence of postoperative complications, such as vocal cord palsy, wound infection, subcutaneous emphysema, pneumothorax, chylothorax, new onset of atrial fibrillation, and in-hospital death. Pain was assessed using the numeric rating scale, by asking patients to rate their pain on a scale of 0 (no pain) to 10 (disabling pain). The quality of postoperative recovery was assessed using the global Quality of Recovery-40 (QoR-40) questionnaire at postoperative 24 and $72 \mathrm{~h}$. This questionnaire consisted of 40 questions that examined 5 domains of patient recovery, namely physical comfort, physical independence, psychological support, emotional state, and pain. The global QoR-40 scores range from 40 to 200 , representing very poor to outstanding recovery. Poor recovery is defined as $<1$ standard deviation below the group mean in $\geq 2$ dimensions or a global QoR-40 score of $<1$ standard deviation of the group mean. The postoperative consumption of 
rescue analgesics was converted to the equianalgesic dose of IV morphine [8].

\section{Statistical analysis}

Based on 5 preliminary patients, we identified that the epidural PCA requirement during the first $24 \mathrm{~h}$ of surgery was $68.7 \pm 20.2 \mathrm{ml}$. With a sample size of $17 \mathrm{pa}$ tients in each group, a total of 34 patients were calculated to obtain a statistical power of $80 \%$ at a significance level of 0.05 (2-tailed) to reduce $30 \%$ of epidural PCA requirement. The Initiative on Methods, Measurement, and Pain Assessment in Clinical Trials (IMMPACT) II consensus recommended that a 30\% reduction in pain from baseline can be considered significant in chronic pain clinical trial [9]. Thus, reduction by $30-35 \%$ in pain intensity was rated as minimal clinically important difference in postoperative pain $[10,11]$. In these contexts, we decided that $30 \%$ was the expected reduction rate. To allow for $15 \%$ drop-out during the study period, we recruited a total of 40 patients. Continuous variables such as epidural PCA consumption at 24 and $72 \mathrm{~h}$, pain intensity score at resting and coughing, rescue drug dose, ICU stay and hospital stay were presented as the mean \pm standard deviation or medians with the range, and were analyzed using the paired $t$ test or Mann-Whitney rank-sum U test. Categorical variables such as the incidence of shoulder pain, nausea, vomiting, vocal cord palsy, wound infection, respiratory complication, subcutaneous emphysema, pneumonia, chylothorax, in-hospital death and poor recovery profile at POD 1 and 3, and new onset of atrial fibrillation were presented as frequencies and percentages and assessed using the Pearson's $\chi^{2}$ or Fisher's exact test. Repeatedly measured data, such as QoR-40 and perioperative hemodynamics, were analyzed using 2-way analysis of variance. Statistical analyses were conducted using SPSS (Version 21.0; SPSS Inc., Chicago, IL, USA). In all comparisons, $P<0.05$ was considered statistically significant.

\section{Results}

Between December 2011 and October 2012, 40 patients were enrolled in this prospective, randomized, double-blind study. All patients were randomly allocated to the control (group C) or dexamethasone (group D) groups. Among the enrolled patients, 2 were excluded because they did not want to participate (1 patient each in both groups). Therefore, 38 patients were included in the final analysis (Fig. 1).

In the final analysis, group $\mathrm{C}$ and $\mathrm{D}$ included $19 \mathrm{pa-}$ tients each. No significant differences were observed in the demographic data or perioperative characteristics of these groups (Table 1). The cumulative consumption of epidural PCA did not differ between groups $C$ and D at $24 \mathrm{~h}$ (63.6 [55.9-72.7] vs. $68.5[60.2-89.0] \mathrm{ml}, P=0.281)$ and $72 \mathrm{~h}$ (199.4 [172.4-225.1] vs. 194.7 [169.1-252.2] $\mathrm{ml}, P=0.890)$. Other outcomes, such as the pain

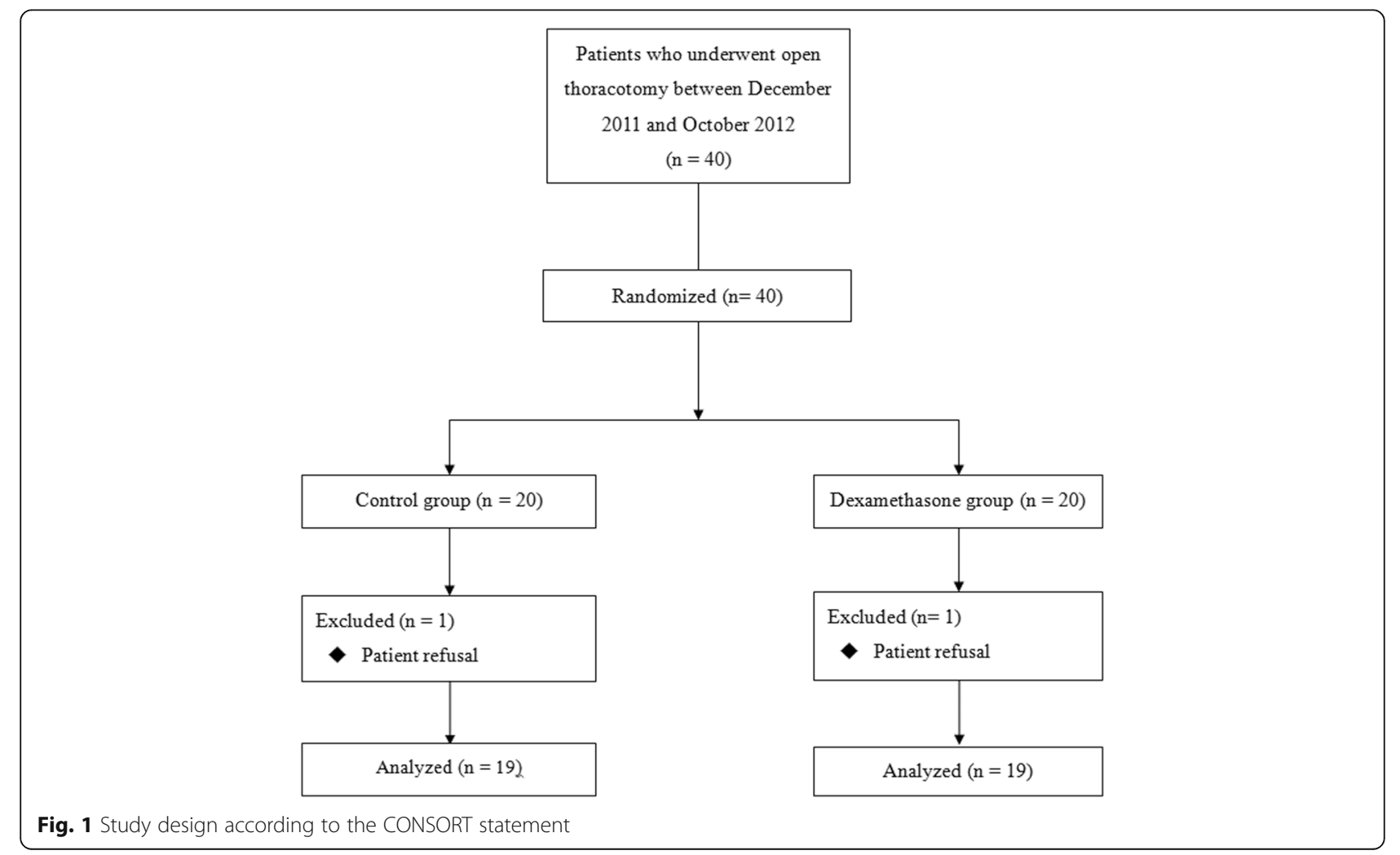


Table 1 Demographic and clinical characteristics of the subjects according to dexamethasone

\begin{tabular}{|c|c|c|}
\hline & Control $(n=19)$ & Dexamethasone $(n=19)$ \\
\hline \multicolumn{3}{|l|}{ Demographics } \\
\hline Age (years) & $65.60 \pm 7.94$ & $66.50 \pm 8.44$ \\
\hline Female sex & $5(26.3)$ & $6(31.6)$ \\
\hline Body mass index $\left(\mathrm{kg} / \mathrm{m}^{2}\right)$ & $24.20 \pm 2.44$ & $24.54 \pm 2.48$ \\
\hline \multicolumn{3}{|l|}{ ASA class } \\
\hline I & 5 & 2 \\
\hline$\|$ & 14 & 17 \\
\hline \multicolumn{3}{|l|}{ Legion location } \\
\hline Right upper lobe & 6 & 6 \\
\hline Right middle lobe & 2 & 1 \\
\hline Right lower lobe & 5 & 6 \\
\hline Left upper lobe & 1 & 2 \\
\hline Left lower lobe & 5 & 4 \\
\hline \multicolumn{3}{|c|}{ Laboratory data } \\
\hline Hematocrit (\%) & $39.23 \pm 2.77$ & $38.63 \pm 2.92$ \\
\hline Creatinine (mg/dL) & $0.74[0.64-0.84]$ & $0.76[0.67-0.98]$ \\
\hline Albumin (g/dL) & 3.80 [3.70-3.98] & 3.85 [3.33-4.20] \\
\hline C-reactive protein (mg/dL) & $0.20[0.10-1.78]$ & $0.52[0.11-1.48]$ \\
\hline Glucose (mg/dL) & 115 [107-142] & 126 [106-156] \\
\hline Sodium (mmol/L) & 140 [137-142] & 140 [137-142] \\
\hline Potassium (mmol/L) & $4.25 \pm 0.21$ & $4.29 \pm 0.36$ \\
\hline \multicolumn{3}{|l|}{ Pulmonary function test } \\
\hline FVC (\% predicted) & $93.06 \pm 16.07$ & $85.19 \pm 11.48$ \\
\hline $\mathrm{FEV}_{1}(\%$ predicted $)$ & $88.72 \pm 20.31$ & $81.52 \pm 16.99$ \\
\hline $\mathrm{FEV}_{1} / \mathrm{FVC}$ & $69.05 \pm 11.42$ & $68.55 \pm 10.60$ \\
\hline \multicolumn{3}{|l|}{ Medical history } \\
\hline Diabetes mellitus & $3(15.79)$ & $5(26.32)$ \\
\hline Hypertension & $5(26.32)$ & $6(31.58)$ \\
\hline Dyslipidemia & $3(15.79)$ & $4(21.05)$ \\
\hline Smoker, current & $5(26.32)$ & $4(21.05)$ \\
\hline \multicolumn{3}{|l|}{ Intraoperative data } \\
\hline \multicolumn{3}{|l|}{ Anesthetic agent } \\
\hline Propofol (mg) & $1084.5 \pm 301.4$ & $1157.8 \pm 390.4$ \\
\hline Remifentanil $(\mu \mathrm{g})$ & $5530.4 \pm 1879.1$ & $6428.0 \pm 3616.3$ \\
\hline Anesthetic time (min) & 237.5 [211.3-301.3] & $257.5[230.0-322.5]$ \\
\hline Operation time (min) & 165.0 [145.0-236.5] & $192.5[165.0-251.3]$ \\
\hline \multicolumn{3}{|l|}{ Intraoperative infused volume } \\
\hline Crystalloid (L) & $1.0[0.8-1.6]$ & $1.1[0.8-1.4]$ \\
\hline Colloid (L) & $0.6[0-1.0]$ & $0.6[0.4-1.0]$ \\
\hline Urine output (mL) & 207.5 [132.5-377.5] & $240.0[112.5-802.5]$ \\
\hline Use of vasopressor, n & $12(63.16)$ & $11(57.90)$ \\
\hline
\end{tabular}


intensity score during resting and coughing, shoulder pain, postoperative consumption of rescue analgesics, and incidence of nausea and vomiting, were also not significantly different (Table 2). Moreover, the QoR-40 scores showed no significant differences between both global and individual categories (Table 3). No differences were observed in hospital stay, intensive care unit stay, or incidence of postoperative complications between the two groups (Table 4).

\section{Discussion}

The present study shows that a preemptive single administration of dexamethasone $(0.1 \mathrm{mg} / \mathrm{kg})$ does not reduce the cumulative epidural PCA consumption during postoperative period.

To treat post-thoracotomy pain, we believe that the multimodal approach is important because pain after thoracotomy is caused by a multifactorial pathophysiology. The mechanisms underlying post-thoracotomy pain include nociceptive somatic and visceral mechanisms, neuropathic mechanisms, and referred pain. Somatic tissue injuries are caused by factors such as skin incision; rib retraction; muscle splitting; and injury of parietal pleura afferent through intercostal nerves and ipsilateral dorsal horn of the spinal cord and are transmitted to the limbic system and somatosensory cortex of the contralateral anterolateral system of the spinal cord. Injury to visceral tissues, such as bronchi, visceral pleura, and pericardium, are transmitted via phrenic and vagus nerves. These nociceptive stimuli increase inflammatory mediators, which is directly activate and enhance the nociceptor activity. This mechanism is called primary sensitization and causes acute pain after thoracotomy [12, 13]. The most common TEA regimen is a combination of local anesthetics and opioids. Local anesthetics in TEA enhance the bioavailability of opioids in the cerebrospinal fluid, increase binding to the mu receptor, and reduce the release of inflammatory mediators in the spinal cord. However, because the main mechanism of TEA is to block the central transmission of nociceptive stimuli, it does not block the peripheral nociception itself. Moreover, TEA does not reduce referred pain. Thus, the addition of local anesthetics or combination of anti-inflammatory drugs is considered to be a good multimodal approach to treat thoracotomy pain because it blocks peripheral nociception [12, 14, 15].

In our knowledge, to date, no study has reported the effect of the combination of epidural analgesia and IV steroids on post-thoracotomy pain. The pain relief properties of steroids are well established in metastatic bone, neuropathic, and visceral pain. Glucocorticoids confer anti-inflammatory effects by inhibiting prostaglandin synthesis and reduce tissue edema by modulating vascular permeability. Moreover, steroids reduce the spontaneous discharge of injured nerves $[16,17]$. Dexamethasone is the most widely used glucocorticoid for the management of pain because it has less mineralocorticoid effects, is relatively more potent, and has a longer half-life than do other corticosteroids [18]. Some studies have suggested that the single use of dexamethasone effectively alleviates postoperative pain as an adjuvant treatment option. Feroci et al. [4] reported that dexamethasone reduces the incidence of postoperative nausea and vomiting (PONV) and post-thyroidectomy pain. Fukami et al. [5] also reported that preoperative dexamethasone reduces the incidence of PONV, fatigue, and pain after laparoscopic cholecystectomy. Similar results have been reported in other surgeries, such as orofacial, urethral, and orthopedic surgeries [2, 19-22].

However, dexamethasone showed no analgesic effects in the present study. These results may be explained by the doses of dexamethasone. We used a relatively small dose of the drug $(0.1 \mathrm{mg} / \mathrm{kg})$ because corticosteroids may have various side effects, such as weight gain, muscle weakness, insomnia, and infection [18]. A recent

Table 2 Primary and secondary outcomes according to dexamethasone administration

\begin{tabular}{|c|c|c|c|c|c|c|}
\hline & \multicolumn{3}{|l|}{ POD 1} & \multicolumn{3}{|l|}{ POD 3} \\
\hline & Control $(n=19)$ & Dexamethasone $(n=19)$ & $p$ & Control $(n=19)$ & Dexamethasone $(n=19)$ & $p$ \\
\hline Epidural PCA (mL) & $63.6[55.9-72.7]$ & $68.5[60.2-89.0]$ & 0.281 & 199.4 [172.4-225.1] & 194.7 [169.1-252.2] & 0.890 \\
\hline \multicolumn{7}{|l|}{ NRS } \\
\hline Rest & $3.0[1.4-4.0]$ & $3.0[1.0-4.5]$ & 0.975 & $2[1.5-3.0]$ & 2 [1.0-2.5] & 0.549 \\
\hline Cough & $3.0[3.0-8.0]$ & $3.8[3.0-5.8]$ & 0.781 & $3.0[3.0-6.0]$ & $3.0[2.0-5.0]$ & 0.369 \\
\hline Shoulder pain & $5(26.32 \%)$ & $2(10.53 \%)$ & 0.405 & $4(21.05 \%)$ & $3(15.79 \%)$ & 1.000 \\
\hline Rescue drug (mg) & 10 [10-20] & 10 [10-20] & 0.453 & $2.5[0-26]$ & $2.5[0-19]$ & 0.862 \\
\hline Nausea & $2(10.53 \%)$ & $2(10.53 \%)$ & 1.000 & $1(5.26 \%)$ & $1(5.26 \%)$ & 1.000 \\
\hline Vomiting & $0(0 \%)$ & 1 (5.26\%) & 1.000 & $0(0 \%)$ & $0(0 \%)$ & 1.000 \\
\hline
\end{tabular}

Data are expressed as the number of patients (\%) or median [first-third quartiles]

$P O D$ post-operative day, $P C A$ patient-controlled analgesia, NRS numerical rating scale 
Table 3 Quality of Recovery-40 scores according to dexamethasone administration

\begin{tabular}{|c|c|c|c|c|}
\hline & Preoperative & POD1 & POD3 & $p$ \\
\hline \multicolumn{5}{|l|}{ QoR_Global } \\
\hline Control & 187 [176-194] & 174 [164-189] & 189 [178-191] & \multirow[t]{2}{*}{0.625} \\
\hline Dexamethasone & 187 [166-195] & 182 [170-193] & 190 [177-194] & \\
\hline \multicolumn{5}{|l|}{ Physical comfort } \\
\hline Control & 56 [54-59] & $53[48-56]$ & $57[54-58]$ & \multirow[t]{2}{*}{0.857} \\
\hline Dexamethasone & 56 [53-60] & 55 [51-59] & 57 [50-60] & \\
\hline \multicolumn{5}{|c|}{ Physical independence } \\
\hline Control & 25 [25-25] & 20 [15-22] & 22 [19-25] & \multirow[t]{2}{*}{0.213} \\
\hline Dexamethasone & 25 [23-25] & 25 [18-25] & 23 [21-25] & \\
\hline \multicolumn{5}{|c|}{ Psychological support } \\
\hline Control & 33 [31-35] & 35 [29-35] & 35 [34-35] & \multirow[t]{2}{*}{0.625} \\
\hline Dexamethasone & 33 [29-35] & 35 [34-35] & 35 [35-35] & \\
\hline \multicolumn{5}{|l|}{ Emotional state } \\
\hline Control & $42[41-43]$ & $42[38-45]$ & $43[42-45]$ & \multirow[t]{2}{*}{0.967} \\
\hline Dexamethasone & $41[36-44]$ & 42 [39-45] & $44[40-45]$ & \\
\hline \multicolumn{5}{|l|}{ Pain } \\
\hline Control & 35 [32-35] & 32 [27-34] & 32 [29-35] & \multirow[t]{2}{*}{0.940} \\
\hline Dexamethasone & 35 [32-35] & 31 [28-33] & $33[31-35]$ & \\
\hline
\end{tabular}

Data are expressed as the median [first-third quartiles]

QoR Quality of Recovery, $P O D$ post-operative day

meta-analysis reported that low-dose dexamethasone $(\leq 0.1 \mathrm{mg} / \mathrm{kg})$ does not reduce postoperative pain, although perioperative high-dose dexamethasone (> $0.1 \mathrm{mg} / \mathrm{kg}$ ) confers this effect [23]. Moreover, the incidences of referred pain and PONV in this study were not different in the two groups. As mentioned earlier, TEA itself does not reduce referred pain, if preemptive dexamethasone is effective, postoperative referred pain should be reduce. With respect to PONV prevention, there is no need for further mentioning the effects of dexamethasone. Thus, we believe that the effect of a single, relatively small dose of dexamethasone is insufficient in treating thoracotomy pain. Another reason for the results may be explained that the "single" administration

Table 4 Post-operative outcomes according to dexamethasone administration

\begin{tabular}{llll}
\hline & Control $(n=19)$ & Dexamethasone $(n=19)$ & $p$ \\
\hline ICU stay (hours) & $21.5[17.3-24.0]$ & $22.5[20.0-23.0]$ & 0.643 \\
Hospital stay (days) & $6[5-8]$ & $6[5-8]$ & $4(21.05 \%)$ \\
Shoulder pain & $7(36.84 \%)$ & $0(0)$ & 0.967 \\
Vocal cord palsy & $3(15.79 \%)$ & $0(0)$ & 0.474 \\
Wound infection & $1(5.26 \%)$ & $7(36.84 \%)$ & 0.230 \\
Respiratory complication & $5(26.32 \%)$ & $2(10.53 \%)$ & 1.000 \\
Subcutaneous emphysema & $1(5.26 \%)$ & $4(21.05 \%)$ & 0.727 \\
Pneumonia & $1(5.26 \%)$ & $2(10.53 \%)$ & 0.000 \\
Chylothorax & $2(10.53 \%)$ & $18[10-35]$ & 1.000 \\
In-hospital death & $0(0 \%)$ & $10(52.6 \%)$ & 1.000 \\
Rescue analgesic drug, total (mg) & $25[10-39]$ & $10(52.6 \%)$ & 0.549 \\
Poor QoR day1 & $15(78.9 \%)$ & $1(5.26 \%)$ & 0.171 \\
Poor QoR day3 & $13(68.4 \%)$ & & 0.507 \\
Postoperative atrial fibrillation & $4(21.05 \%)$ & 0.340 \\
\hline
\end{tabular}

Data are expressed as the number of patients (\%) or median [first-third quartiles] ICU intensive care unit, QoR quality of recovery 
of dexamethasone in the preoperative period. Senard et al. [24] reported that the combination of TEA and parenteral cyclooxygenase (COX)-2 inhibitor (NSAID) reduces post-thoracotomy pain. We believe that dexamethasone and NSAIDs have similar mechanisms for treating post-thoracotomy pain by inhibiting COX. However, the main results reported by Senard and those of the present study are different. In Senard's study, patients received parenteral COX-2 from the evening before surgery until postoperative $48 \mathrm{~h}$. Craig et al. [25] reported that the inflammatory response after a thoracotomy incision peaked at approximately $48 \mathrm{~h}$ after surgery. Therefore, a preemptive single administration of dexamethasone may be insufficient in controlling post-thoracotomy pain. Lastly, in the present study, the effect of dexamethasone might be masked by the highly potent TEA regimen. This theory may explain the results of QoR-40. The QoR-40 scores did not differ between the two groups, and there was no difference between preoperative and postoperative periods either. This suggests that pain management for thoracotomy in the present study may be enough for the TEA itself.

The present study has some limitations. First, we did not perform a dose-dependent analysis and did not examine the effects of multiple doses. Second, we did not measure the pain intensity score during the immediate postoperative period. Because patients are unstable immediately after thoracotomy, the measurement of the pain intensity score might not be feasible. Furthermore, we administered epidural PCA during the closure of the muscle layer because the pain-reducing effects of epidural PCA are so effective that the combination effects of dexamethasone are often masked. Third, we did not examine chronic, neuropathic pain. Nociceptive stimuli occur continuously during the perioperative period; it leads to the hyperexcitability of the dorsal horn and may develop progress chronic, neuropathic pain. Dexamethasone reduces the spontaneous discharge of injured nerves. Our finding reflects that dexamethasone may be more effective against chronic, neuropathic pain than against acute pain. Finally, we only included 40 patients and acknowledged that additional, larger, dose-dependent, and time-dependent studies are required to elucidate the effects of dexamethasone on post-thoracotomy pain. To overcome these limitations, we think that dose-dependent, long-term outcome study should be needed to evaluate the effects of dexamethasone on post-thoracotomy pain.

\section{Conclusion}

The single administration of dexamethasone during the preoperative period does not reduce post-thoracotomy pain during the recovery period.

\section{Abbreviations}

COX-2: Cyclo-oxygenase 2; ICU: Intensive care unit; PCA: Patient-controlled analgesia; QoR: Quality of recovery

\section{Funding}

None

Availability of data and materials

The datasets used and/or analysed during the current study are available from the corresponding author on reasonable request.

\section{Authors' contributions}

K-WJ, E-HL drafted the manuscript, performed statistical analysis and designed the trial. K-WJ, H-RK, W-JK, YJL and I-CC performed the study and obtained data. E-HL and I-CC designed the trial and performed the study. JWK contributed data interpretation and analysis, and involved in revising the manuscript. All authors contributed substantially to its revision. E-HL takes responsibility for the paper as a whole. All authors read and approved the final manuscript.

\section{Ethics approval and consent to participate}

We was obtained approval from our institutional review board (AMC-IRB, No: 2011-0812) and written informed consent from each patient.

Consent for publication

Not applicable

Competing interests

The authors declare that they have no competing interests.

\section{Publisher's Note}

Springer Nature remains neutral with regard to jurisdictional claims in published maps and institutional affiliations.

\section{Author details}

${ }^{1}$ Department of Anesthesiology and Pain Medicine, Laboratory for Perioperative Outcomes Analysis and Research, Asan Medical Center, University of Ulsan College of Medicine, 88 Olympic-ro 43-gil, Songpa-gu, Seoul 05505, Korea. ${ }^{2}$ Department of Thoracic and Cardiovascular Surgery, Asan Medical Center, University of Ulsan College of Medicine, Seoul, Korea. ${ }^{3}$ Department of Anesthesiology and Pain Medicine, Asan Medical Center, University of Ulsan College of Medicine, Seoul, Korea.

Received: 11 December 2017 Accepted: 20 September 2018

Published online: 27 September 2018

\section{References}

1. Ali M, Winter DC, Hanly AM, O'Hagan C, Keaveny J, Broe P. Prospective, randomized, controlled trial of thoracic epidural or patient-controlled opiate analgesia on perioperative quality of life. Br J Anaesth. 2010;104:292-7.

2. Baxendale BR, Vater $M$, Lavery KM. Dexamethasone reduces pain and swelling following extraction of third molar teeth. Anaesthesia. 1993;48: 961-4.

3. Beirne OR, Hollander B. The effect of methylprednisolone on pain, trismus, and swelling after removal of third molars. Oral Surg Oral Med Oral Pathol. 1986;61:134-8.

4. Feroci F, Rettori M, Borrelli A, Lenzi E, Ottaviano A, Scatizzi M. Dexamethasone prophylaxis before thyroidectomy to reduce postoperative nausea, pain, and vocal dysfunction: a randomized clinical controlled trial. Head Neck. 2011;33:840-6.

5. Fukami Y, Terasaki M, Okamoto Y, Sakaguchi K, Murata T, Ohkubo M, et al. Efficacy of preoperative dexamethasone in patients with laparoscopic cholecystectomy: a prospective randomized double-blind study. J HepatoBiliary-Pancreat Surg. 2009;16:367-71.

6. Thangaswamy CR, Rewari V, Trikha A, Dehran M, Chandralekha. Dexamethasone before total laparoscopic hysterectomy: a randomized controlled dose-response study. Journal of Anesthesia. 2010;24:24-30.

7. Waldron NH, Jones CA, Gan TJ, Allen TK, Habib AS. Impact of perioperative dexamethasone on postoperative analgesia and side-effects: systematic review and meta-analysis. Br J Anaesth. 2013;110:191-200. 
8. Scott M, Fishman JCB, James P. Rathmell: Bonica's management of pain. 4th ed. Lippincott: Willams \& Wilkins; 2010.

9. Dworkin RH, Turk DC, Wyrwich KW, Beaton D, Cleeland CS, Farrar JT, et al. Interpreting the clinical importance of treatment outcomes in chronic pain clinical trials: IMMPACT recommendations. J Pain. 2008;9:105-21.

10. Cepeda MS, Africano JM, Polo R, Alcala R, Carr DB. What decline in pain intensity is meaningful to patients with acute pain? Pain. 2003;105:151-7.

11. Jensen MP, Chen C, Brugger AM. Interpretation of visual analog scale ratings and change scores: a reanalysis of two clinical trials of postoperative pain. J Pain. 2003;4:407-14.

12. Mesbah A, Yeung J, Gao F. Pain after thoracotomy. BJA Educ. 2016;16:1-7.

13. Doan LV, Augustus J, Androphy R, Schechter D, Gharibo C. Mitigating the impact of acute and chronic post-thoracotomy pain. J Cardiothorac Vasc Anesth. 2014;28:1048-56.

14. Gerner P. Postthoracotomy pain management problems. Anesthesiol Clin. 2008:26:355-67 vii.

15. Gottschalk A, Cohen SP, Yang S, Ochroch EA. Preventing and treating pain after thoracic surgery. Anesthesiology. 2006;104:594-600.

16. Mensah-Nyagan AG, Meyer L, Schaeffer V, Kibaly C, Patte-Mensah C. Evidence for a key role of steroids in the modulation of pain. Psychoneuroendocrinology. 2009;34(Suppl 1):S169-77.

17. Watanabe S, Bruera E. Corticosteroids as adjuvant analgesics. J Pain Symptom Manag. 1994;9:442-5.

18. Vyvey M. Steroids as pain relief adjuvants. Can Fam Physician. 2010;56: 1295-7.

19. Asad MV, Khan FA. Effect of a single bolus of dexamethasone on intraoperative and postoperative pain in unilateral inguinal hernia surgery. J Anaesthesiol Clin Pharmacol. 2015;31:339-43.

20. Bigat Z, Boztug N, Hadimioglu N, Cete N, Coskunfirat N, Ertok E. Does dexamethasone improve the quality of intravenous regional anesthesia and analgesia? A randomized, controlled clinical study. Anesth Analg. 2006;102:605-9.

21. Desmet M, Braems H, Reynvoet M, Plasschaert S, Van Cauwelaert J, Pottel H, et al. I.V. and perineural dexamethasone are equivalent in increasing the analgesic duration of a single-shot interscalene block with ropivacaine for shoulder surgery: a prospective, randomized, placebo-controlled study. $\mathrm{Br} J$ Anaesth. 2013;111:445-52

22. Lee C, Kim TY. The effect of preoperative dexamethasone administration, according to age and gender on postoperative pain in patients who undergo laparoscopic Choelecystectomy. Korean J Pain. 2008;21:51-6.

23. De Oliveira GS Jr, Almeida MD, Benzon HT, McCarthy RJ. Perioperative single dose systemic dexamethasone for postoperative pain: a meta-analysis of randomized controlled trials. Anesthesiology. 2011;115:575-88.

24. Senard M, Deflandre EP, Ledoux D, Roediger L, Hubert BM, Radermecker M, et al. Effect of celecoxib combined with thoracic epidural analgesia on pain after thoracotomy. Br J Anaesth. 2010;105:196-200.

25. Craig SR, Leaver HA, Yap PL, Pugh GC, Walker WS. Acute phase responses following minimal access and conventional thoracic surgery. Eur J Cardiothorac Surg. 2001;20:455-63.

Ready to submit your research? Choose BMC and benefit from:

- fast, convenient online submission

- thorough peer review by experienced researchers in your field

- rapid publication on acceptance

- support for research data, including large and complex data types

- gold Open Access which fosters wider collaboration and increased citations

- maximum visibility for your research: over $100 \mathrm{M}$ website views per year

At $\mathrm{BMC}$, research is always in progress.

Learn more biomedcentral.com/submissions 